\title{
New procedures affecting the conduct of clinical trials in the United Kingdom
}

\author{
J P GRIFFIN, J R LONG
}

\begin{abstract}
Changes have recently been introduced to facilitate the conduct of clinical trials of new drugs in the United Kingdom. These changes became necessary because early developmental work on new drugs was going abroad to the detriment of British industry and with a loss of skill in our departments of clinical pharmacology. The scheme also gives formal recognition to the part played by ethics committees in considering approval of the ethical aspects of clinical trials of new drugs.
\end{abstract}

\section{Introduction}

In his speech at the annual dinner of the Association of the British Pharmaceutical Industry in April 1980 Mr Patrick Jenkin, Secretary of State for Social Services, talking about the regulatory requirements for clinical trials, said, "Even before I became Secretary of State, I was aware that in this area the United Kingdom was out of line with practically all other developed countries; that our requirements were unnecessarily rigorous and inflexible; and that as a consequence early developmental work on new drugs was going abroad, to the detriment of the United Kingdom industry and with a loss of expertise in our departments of clinical pharmacology." To meet these criticisms, the Secretary of State approved the Medicines Division's proposals for a new scheme under which pharmaceutical

Department of Health and Social Security, London SW8 5 NQ J P GRIFFIN, PHD, MRCP, senior principal medical officer J R LONG, assistant secretary, medicines division companies could seek exemption from the need to obtain a clinical trial certificate before beginning trials on patients. This article indicates the broad outlines of the new scheme introduced in March 1981 and also the role envisaged for ethics committees. It draws attention in particular to features likely to be of interest to doctors who conduct clinical studies or who serve on ethics committees.

\section{Old scheme}

The Medicines Act 1968 set up a licensing authority for medicinal products, consisting of the health and agriculture ministers of the United Kingdom, and provided for the establishment of expert committees-of which the Committee on Safety of Medicines is the best known-to advise the licensing authority. When the licensing provisions of the Act came into force in 1971, companies were prohibited from initiating clinical trials of new products, or of new uses for existing products, without first obtaining from the licensing authority a clinical trial certificate for the compound. This carried forward into a statutory form arrangements first introduced by the Committee on Safety of Drugs. The intention was that the licensing authority, helped as necessary by the Committee on Safety of Medicines, would assess the potential toxicity of the compound in relation to the proposed use before granting a certificate. This entailed careful positive vetting of all the data submitted by the company in accordance with guidelines issued by the licensing authority. In these respects, the United Kingdom regulations were, and have remained, more rigorous than those of most other regulatory authorities.

In 1972 doctors and dentists wishing to conduct trials on their own initiative-that is, not prompted by a third party-were permitted to do so without a clinical trial certificate provided 
that they notified their intention in prescribed form and no objection was raised by the licensing authority. ${ }^{1}$ Underlying this exemption scheme was the view that in these circumstances less stringent control was necessary and that patients could be safeguarded against undue hazard by operating the "long-stop" mechanism that if, on negative vetting, the licensing authority thought that the trial was unjustified it could refuse an exemption. This scheme has stood the test of time in that, as shown in table I the number of such trials has grown, without any untoward effect on patient safety.

TABLE I-Exemptions from certification of trials conducted by doctors and dentists on their own initiative

\begin{tabular}{lccccccccc}
\hline & 1972 & 1973 & 1974 & 1975 & 1976 & 1977 & 1978 & 1979 & 1980 \\
\hline $\begin{array}{l}\text { No of exemptions } \\
\text { granted }\end{array}$ & 49 & 203 & 201 & 200 & 184 & 241 & 284 & 356 & 320 \\
\hline
\end{tabular}

Over the same period, bearing out the concern expressed by the Secretary of State, the number of clinical trials initiated by companies has progressively declined (table II). Two of the reasons advanced by the industry for this decline have been that excessive demands were made for pharmaceutical and toxicological data before trials in patients were allowed to begin, and that the processing of an application for a clinical trial certificate through the licensing authority presented companies with an unacceptable delay of several months. These delays have sometimes been over eight months, depending on the number of staff within the Medicines Division. As a result, according to

TABLE II-Clinical trial certificates granted

\begin{tabular}{rrrrrrrrrr}
\hline & 1972 & 1973 & 1974 & 1975 & 1976 & 1977 & 1978 & 1979 & 1980 \\
\hline No of CTCs granted & 170 & 179 & 169 & 139 & 140 & 105 & 107 & 106 & 87
\end{tabular}

industry spokesmen, companies have been forced to conduct early clinical studies abroad rather than in the United Kingdom. In reporting the December 1979 meeting of the MedicoPharmaceutical Forum, Dr B W Cromie quoted T J Thomson as claiming that $60 \%$ of early clinical trials of molecules originating within the British pharmaceutical industry were being conducted abroad. ${ }^{2}$

\section{New scheme}

The question of excessive requirements for pharmaceutical and toxicological data was taken up by the Committee on Safety of Medicines, and recommendations made by a working party chaired by Professor Grahame-Smith will shortly be implemented. To meet the Secretary of State's wishes for procedural changes, a new scheme for dealing with proposed clinical trials was introduced in March $1981 .^{3}$ While pharmaceutical companies are still required to generate the same basic data to support the clinical study proposed (as laid down in notes for guidance to applicants as revised from time to time by the licensing authority), they are required to send to the licensing authority only certified summaries of these and any other relevant data, together with a copy of the protocol, and confirmation by a doctor working in the United Kingdom who is the medical adviser or medical consultant to the company that he has satisfied himself that in the light of the information submitted it is reasonable for the trial to take place.
The licensing authority then has 35 days in which to consider the notification and summarised data and advise the company whether or not it objects to the proposed trials. There is no formal appeal if the licensing authority refuses to grant an exemption, but the company may still then apply for a clinical trial certificate as before; this will generally mean the application being referred to the Committee on Safety of Medicines for advice and the company having the right to make representations to the committee. An exemption may be withdrawn forthwith if doubts are raised subsequently about the safety of the product. The exemption holder is obliged to notify the licensing authority of changes made to the protocol, of adverse reactions to the product arising during the trial, and of any other information casting doubt on safety. He is also required to notify the licensing authority if an ethics committee withholds approval for the trial.

\section{Ethics committees}

This will mean that from now on ethics committees may find themselves concerned with clinical trials that have been subject to three different types of regulatory scrutiny: (a) those in which the safety and quality of the compound has been assessed by the licensing authority as fully as is practicable at the stage of development, $(b)$ those under the new scheme under which summarised data has been subject to "negative vetting" by the licensing authority, on the basis of which it has seen no reason to object to the trial, and (c) generally small-scale trials initiated by a doctor or dentist in which a minimum of information has been seen by the licensing authority.

Companies, as opposed to individual practitioners, will be the sponsors of trials in groups $(a)$ and $(b)$. They are being advised that when submitting a protocol to an ethics committee they should either (i) state that a clinical trial certificate has been issued or that the trial has been exempted or (ii) explain that a certificate or exemption is being sought and undertake to let the ethics committee know of any important change that might be agreed as a result of discussion with the licensing authority. An important point for members of ethics committees to appreciate is that the licensing authority is not looking to them to make any distinction between certificates and exemptions when they scrutinise the protocol. In the case of exempted trials there is no extra responsibility for the ethics committee to consider the possible quality or safety aspects of a drug beyond the consideration that they would ordinarily give to such matters in general. No change in their role in this respect is envisaged: it remains to consider the ethics of the trial as a whole in the way they have always done when a doctor has initiated a trial without the suggestion of a pharmaceutical company.

\section{Benefits expected}

The benefits expected from this change in procedure, and from the contemporaneous review of data requirements, include not only benefits to patients from newly marketed drugs having been adequately tested in the therapeutic environment of the United Kingdom, but also that it enables industry to speed up the "brain-to-bottle time," it encourages the development of departments of clinical pharmacology both from the stimulus of new work and the financial support afforded by the industry, it provides an incentive for the research and development element of the industry to develop in the United Kingdom, and it eases the task of the licensing authority and the Committee on Safety of Medicines in assessing drugs at marketing stage if trials to a high standard have been conducted in the United Kingdom.

The exemption scheme introduces two new concepts. Firstly, counter-signature of the notification of the proposed trial by a doctor associated with the company and based in the United Kingdom (and therefore more readily accessible) to show that he has scrutinised all the relevant data and is prepared to vouch for the soundness of the proposal. Secondly, the scheme gives formal 
recognition to the part played by ethics committees in considering approval of the ethical aspects of clinical trials of new drugs. In the two months since the introduction of the scheme (11 March-11 May) 22 clinical trial certificate exemptions were granted. If this trend continues-and there are indications that it will increase rather than diminish-then there will have been a $50 \%$ increase in early clinical studies conducted in the United Kingdom at the industry's initiative. It therefore appears, even at this early stage, to be achieving its objective.

\section{References}

${ }^{1}$ House of Commons. The Medicines (Exemptions from Licences) (Special Cases and Miscellaneous Provisions) Order 1972. (SI 1972 No 1200.) London: HMSO, 1972.

${ }^{2}$ Cromie BW. Testing new medicines in the UK. $\mathcal{F} R$ Soc Med 1980;73: $379-80$.

${ }^{3}$ House of Commons. The Medicines (Exemptions from Licences) (Clinical Trials) Order 1981. (SI 1981 No 164.) London: HMSO, 1981.

(Accepted 17 fune 1981)

\title{
Lesson of the Week
}

\section{Hydrocephalus after spontaneous subarachnoid haemorrhage}

\author{
SARAH ROBINSON, G HOLDSTOCK
}

In Britain most patients with subarachnoid haemorrhage present to the general physician and are then referred to neurosurgical centres, where they are considered for carotid angiography and surgical correction. On the basis of this they are then either treated surgically or sent back to the referring hospital for conservative management.

We report on two patients with subarachnoid haemorrhage who were not at first thought suitable for surgery and who continued to deteriorate on the medical wards. Both had conditions that could be easily corrected by surgery.

\section{Case reports}

Case 1-A 64-year-old man was admitted to hospital semicomatose, with a two-day history of headache of sudden onset followed by vomiting. His neck was stiff, and a clinical diagnosis of subarachnoid haemorrhage was confirmed by lumbar puncture, which showed heavily blood-stained cerebrospinal fluid (CSF). His general condition improved at first, and he was referred to the neurosurgeons, who recommended conservative treatment in view of his age and history of angina. Over the next two months his condition deteriorated, and he was a severe nursing problem. He was disorientated, dysphagic, doubly incontinent, and developed a marked ataxic gait. He was referred back to the neurosurgical unit for computed tomography (CT), which showed dilated ventricles, and a ventricular atrial shunt was inserted. Almost immediately there was great clinical improvement, and 10 days later he was discharged, having completely returned to normal. Two years later he remains well and has become chairman of the local Rotary Association.

Case 2-A 52-year-old woman was admitted complaining of a severe headache, nausea, and vomiting. She gave a history of mild hypertension and angina. On examination she was drowsy, with marked neck stiffness. Lumbar puncture confirmed the diagnosis of subarachnoid haemorrhage. She underwent

Southampton University Hospitals, Southampton

SARAH ROBINSON, medical student

G HOLDSTOCK, MB, MRCP, senior registrar in medicine
Some patients who have had a subarachnoid haemorrhage and who have been considered unsuitable for surgery may have a hydrocephalus that can be easily corrected

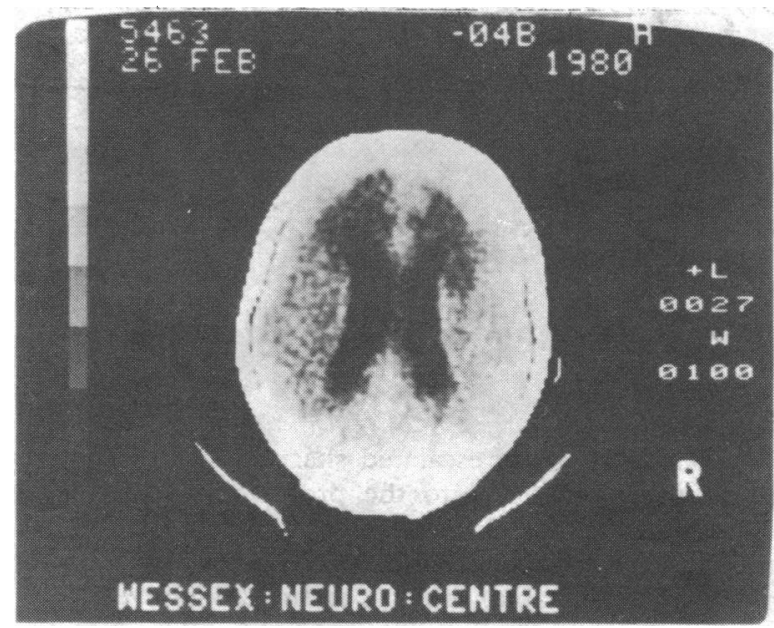

CT scan showing bilaterally dilated intraventricular ventricles.

bilateral carotid arteriography, which showed an anterior communicating and a left-middle cerebral artery aneurysm. These were not thought suitable for surgery, and she returned to the ward having suddenly deteriorated presumably because of a further haemorrhage. Over the next six weeks her general condition deteriorated. She became disorientated, dysphagic, disinterested in her surroundings, doubly incontinent, and unable to walk. A consultant neurologist thought that the most likely diagnosis was a further haemorrhage, but she underwent CT to exclude hydrocephalus, and this showed dilated ventricles (figure). After a Spitz-Holter valve was inserted she made a 